\title{
Chromosome analysis of arsenic affected cattle
}

\author{
S. Shekhar ${ }^{1}$, A. K. Sahoo ${ }^{1}$, N. Dalai ${ }^{2}$, P. Chaudhary ${ }^{1}$, P. K. Praveen ${ }^{3}$, R. Saikhom ${ }^{1}$ and R. Rai ${ }^{4}$
}

1. Department of Animal Genetics and Breeding, West Bengal University of Animal and Fishery Sciences, Kolkata, West Bengal, India; 2. Department of Veterinary Physiology and Biochemistry, West Bengal University of Animal and

Fishery Sciences, Kolkata, West Bengal, India; 3. Department of Veterinary Public Health and Epidemiology, West Bengal University of Animal and Fishery Sciences, Kolkata, West Bengal, India; 4. Department of Livestock Product and Technology, West Bengal University of Animal and Fishery Sciences, Kolkata, West Bengal, India.

Corresponding author: S. Shekhar, e-mail: sshekhar03@rediffmail.com, AKS: profaksahoo@gmail.com, ND: niru.vets@gmail.com,PC: pankaj.choudhury@ymail.com, PKP: drpraveenvet2005@gmail.com, RS: reshmasaikhom@gmail.com, RR: drricharock85@gmail.com

Received: 11-07-2014, Revised: 16-09-2014, Accepted: 22-09-2014, Published online: 26-10-2014

doi: 10.14202/vetworld.2014.859-862. How to cite this article: Shekhar S, Sahoo AK, Dalai N, Chaudhary P, Praveen PK, Saikhom R, Rai R (2014) Chromosome analysis of arsenic affected cattle, Veterinary World 7(10): 859-862.

\begin{abstract}
Aim: The aim was to study the chromosome analysis of arsenic affected cattle.

Materials and Methods: 27 female cattle (21 arsenic affected and 6 normal) were selected for cytogenetical study. The blood samples were collected, incubated, and cultured using appropriate media and specific methods. The samples were analyzed for chromosome number and morphology, relative length of the chromosome, arm ratio, and centromere index of $\mathrm{X}$ chromosome and chromosomal abnormalities in arsenic affected cattle to that of normal ones.

Results: The diploid number of metaphase chromosomes in arsenic affected cattle as well as in normal cattle were all $2 \mathrm{n}=60,58$ being autosomes and 2 being sex chromosomes. From the centromeric position, karyotyping studies revealed that all the 29 pair of autosomes was found to be acrocentric or telocentric, and the sex chromosomes (XX) were submetacentric in both normal and arsenic affected cattle. The relative length of all the autosome pairs and sex chrosomosome pair was found to be higher in normal than that of arsenic affected cattle. The mean arm ratio of X-chromosome was higher in normal than that of arsenic affected cattle, but it is reverse in case of centromere index value of X-chromosome. There was no significant difference of arm ratio and centromere index of X-chromosomes between arsenic affected and normal cattle. No chromosomal abnormalities were found in arsenic affected cattle.
\end{abstract}

Conclusion: The chromosome analysis of arsenic affected cattle in West Bengal reported for the first time in this present study which may serve as a guideline for future studies in other species. These reference values will also help in comparison of cytological studies of arsenic affected cattle to that of various toxicants.

Keywords: arsenic, autosomes, karyotyping, metaphase chromosome.

\section{Introduction}

Arsenic contamination of groundwater in West Bengal, India, is a great concern for both human and livestock population. Arsenic is second only to lead as a cause of heavy metal intoxication in domestic animals. Of the 19 districts of West Bengal, 9 districts having arsenic level of $50 \mu \mathrm{g} / \mathrm{L}$ of water are considered heavily affected, while arsenic level of 4-10 $\mu \mathrm{g} / \mathrm{L}$ of water of five districts are mildly affected and another five districts are less affected [1]. Clinically, arsenic intoxication occurs as an acute or per acute intoxication, although chronic forms of the disease have been observed, especially in cattle. Arsenic intoxication in cattle occurs through ingestion of drinking water, mustard oilcake, crops, and vegetables grown in arsenic-prone zone where arsenic is higher than the permissible limit [2]. It is concluded that straw is also a major source of arsenic contamination in cattle apart from drinking water, and arsenic may enter into human through consumption

Copyright: The authors. This article is an open access article licensed under the terms of the Creative Commons Attributin License (http:// creative commons.org/licenses/by/2.0) which permits unrestricted use, distribution and reproduction in any medium, provided the work is properly cited. of contaminated milk [3]. The comparisons of chromosome aberration frequencies induced by trivalent and pentavalent arsenic have indicated that the trivalent forms are far more potent and genotoxic than the pentavalent forms [4-6]. Arsenic promotes genetic damage in large part by inhibiting DNA repair $[7,8]$. When the source of the intoxication can be found, it is usually herbicides or insecticides containing arsenic. Inorganic arsenic increases the frequency of micronuclei, chromosome aberrations, and sister chromatid exchanges both in humans and animals, but it does not induce point mutations [9].

The main constraints for cattle improvements are insufficient knowledge on chromosome inheritance pattern, different genetic disease, and their chromosomal view. A slight slip in chromosome number or structure brings obvious disorder throughout the life, it may lead to death. Karyotype analysis is an effective way for identification of the disorder of chromosome [10].

With this view, the present investigation has been carried out to study the diploid number, morphology, relative length, and abnormality of metaphase chromosome in arsenic affected cattle in Nadia district which is considered as heavily affected district of West Bengal. 


\section{Materials and Methods}

\section{Ethical approval}

During collection of blood samples: from cattle attention had been paid to minimize pain to the animals and all the samples collection was carried out in accordance with the guidelines laid down by the International Animal Ethics Committee and prevailing local laws and regulations.

\section{Study area}

The present study has been carried out in an arsenic contaminated zone of Nadia District in West Bengal. The experimental animals used in the present study were 27 milch cattle out of which 21 were arsenic affected (above $0.253 \mathrm{ppm}$ ) from two villages namely Gotra and Ramakrishna under Chakda Block of Nadia district in West Bengal which comes under arsenic affected zone $[11,12]$ and 6 were normal from Intensive Livestock Farm Complex, WBUAFS, Kolkata.

\section{Collection of blood samples}

$5 \mathrm{ml}$ blood samples were collected aseptically from jugular veins of each animal in heparinized (125 IU of sodium heparin) vials. Samples were immediately transported to the laboratory on ice.

\section{Preparation of slides and study of metaphase chromosomes}

The metaphase chromosome of each animal was studied using in-vitro whole blood culture technique described by Halnan [13] with some modifications by Eldridge [14]. A total of 108 slides (4 from each animal) from 27 animals was prepared for metaphase chromosome study. Slides were screened under binocular microscope using $\times 10$, and $\times 40$ objectives. 25 metaphase spreads from each slide were examined to ascertain number, morphology and chromosomal abnormalities. One metaphase spread from each coded slide was selected at random and recorded for microphotography using Leica microscope fitted with digital camera with a magnification of $\times 2000$ using oil immersion objective. Four microphotography plates from each animal were taken to measure the length of all the autosomes and sex chromosomes with the help of a dial type of Vernier Caliper with an accuracy of $0.05 \mathrm{~mm}$. The relative length of all the chromosome pairs and the arm ratio, as well as centromere index value, were estimated from the standard formula given by Gerasimchuk [15]. The karyotypes of cattle under study were prepared based on the length of the chromosomes.

\section{Statistical analysis}

The statistical analysis to estimate the mean along with a standard error, analysis of variance, and critical difference (CD) test of significance was made following Snedecor and Cochran [16].

\section{Results}

\section{Chromosome number and morphology}

From the study of 25 metaphase chromosomal spreads from each of total 108 slides as indicated and also as it transpires from the karyotypes of the metaphase spreads, the diploid number of chromosomes in arsenic affected cattle, as well as in normal cattle, were all $2 n=60,58$ being autosomes and 2 being sex chromosomes. From the centromeric position studies, it appeared that all the 29 pair of autosomes was found to be acrocentric or telocentric and the sex chromosomes (XX) were submetacentric in both normal and arsenic affected cattle (Figures-1 and 2).

\section{Relative length of the chromosomes}

The mean relative length and standard error along with the result of the CD test of significance of all the autosomes and sex chromosome pairs based on the measurement from 108 metaphase chromosome spreads (4 from each animal) from 21 arsenic affected cattle and 6 normal cattle have been presented in Table-1. As it appears from Table-1 that the relative length of all the autosome pairs and sex chromosome pair was found to be higher $(6.235 \pm 0.039-1.288 \pm 0.032$ and $3.788 \pm 0.037$, respectively) in normal cattle than that of arsenic affected cattle (5.451 $\pm 0.029-1.281 \pm 0.032$ and $3.765 \pm 0.038$, respectively). From the result of Analysis of variance and CD test of significance, it was found that the relative length of $1^{\text {st }}, 2^{\text {nd }}$, and $3^{\text {rd }}$ pair

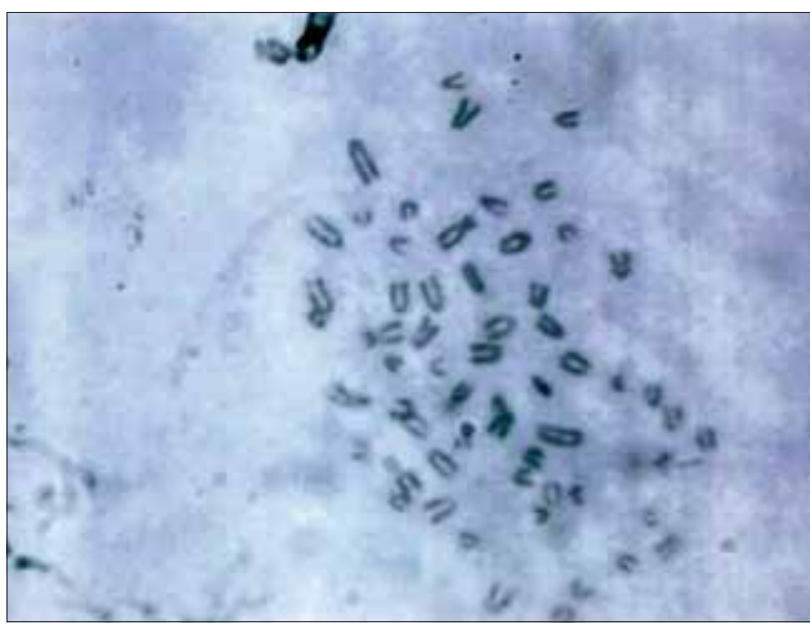

Figure-1: Metaphase spread of normal cattle.

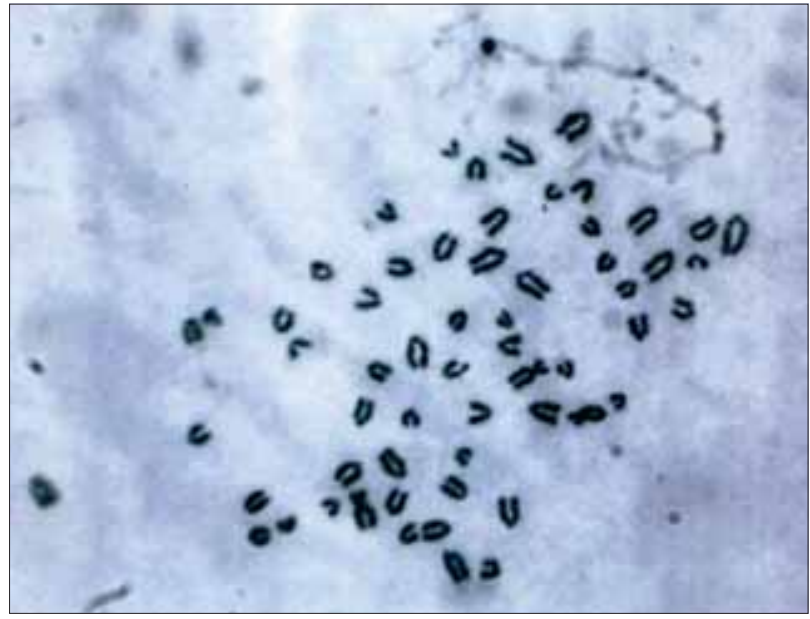

Figure-2: Metaphase spread of arsenic affected cattle. 
Table-1: The means with standard errors of the relative length of different pairs of chromosomes expressed in percentage in the normal and arsenic affected cattle.

\begin{tabular}{lcc}
\hline $\begin{array}{l}\text { Chromosome } \\
\text { pairs }\end{array}$ & $\begin{array}{c}\text { Normal } \\
\mathbf{( 2 4 )}\end{array}$ & $\begin{array}{c}\text { Arsenic affected } \\
\text { cattle (84) }\end{array}$ \\
\hline $1^{\text {st }}$ & $6.235 \pm 0.039^{\mathrm{a}}$ & $5.451 \pm 0.029^{\mathrm{b}}$ \\
$2^{\text {nd }}$ & $6.135 \pm 0.037^{\mathrm{a}}$ & $5.439 \pm 0.031^{\mathrm{b}}$ \\
$3^{\text {rd }}$ & $5.036 \pm 0.041^{\mathrm{a}}$ & $5.431 \pm 0.035^{\mathrm{b}}$ \\
$4^{\text {th }}$ & $4.995 \pm 0.036$ & $4.958 \pm 0.035$ \\
$5^{\text {th }}$ & $4.970 \pm 0.039$ & $4.967 \pm 0.036$ \\
$6^{\text {th }}$ & $4.346 \pm 0.040$ & $4.340 \pm 0.032$ \\
$7^{\text {th }}$ & $4.321 \pm 0.040$ & $4.319 \pm 0.033$ \\
$8^{\text {th }}$ & $3.794 \pm 0.032$ & $3.780 \pm 0.034$ \\
$9^{\text {th }}$ & $3.767 \pm 0.041$ & $3.764 \pm 0.034$ \\
$10^{\text {th }}$ & $3.754 \pm 0.038$ & $3.753 \pm 0.037$ \\
$11^{\text {th }}$ & $3.742 \pm 0.036$ & $3.739 \pm 0.038$ \\
$12^{\text {th }}$ & $3.730 \pm 0.040$ & $3.726 \pm 0.035$ \\
$13^{\text {th }}$ & $3.701 \pm 0.038$ & $3.699 \pm 0.029$ \\
$14^{\text {th }}$ & $3.693 \pm 0.045$ & $3.687 \pm 0.036$ \\
$15^{\text {th }}$ & $3.681 \pm 0.043$ & $3.679 \pm 0.033$ \\
$16^{\text {th }}$ & $2.566 \pm 0.044$ & $2.559 \pm 0.032$ \\
$17^{\text {th }}$ & $2.540 \pm 0.040$ & $2.537 \pm 0.036$ \\
$18^{\text {th }}$ & $2.527 \pm 0.044$ & $2.519 \pm 0.039$ \\
$19^{\text {th }}$ & $2.518 \pm 0.033$ & $2.517 \pm 0.038$ \\
$20^{\text {th }}$ & $2.503 \pm 0.033$ & $2.500 \pm 0.037$ \\
$21^{\text {st }}$ & $2.493 \pm 0.036$ & $2.490 \pm 0.032$ \\
$22^{\text {nd }}$ & $2.478 \pm 0.043$ & $2.471 \pm 0.031$ \\
$23^{\text {td }}$ & $2.465 \pm 0.046$ & $2.459 \pm 0.029$ \\
$24^{\text {th }}$ & $2.453 \pm 0.045$ & $2.449 \pm 0.038$ \\
$25^{\text {th }}$ & $1.340 \pm 0.048$ & $1.319 \pm 0.036$ \\
$26^{\text {th }}$ & $1.331 \pm 0.037$ & $1.317 \pm 0.038$ \\
$27^{\text {th }}$ & $1.326 \pm 0.038$ & $1.315 \pm 0.034$ \\
$28^{\text {th }}$ & $1.305 \pm 0.032$ & $1.301 \pm 0.037$ \\
$29^{\text {th }}$ & $1.288 \pm 0.032$ & $1.281 \pm 0.032$ \\
$X^{-}$ & $3.788 \pm 0.037$ & $3.765 \pm 0.038$ \\
\hline${ }^{4}$ & 59 & \\
\hline
\end{tabular}

Numerics in parenthesis in Table-1 indicate the number of observations

of autosome only in arsenic affected cattle differ significantly $(\mathrm{p}=0.05)$ from that of normal cattle.

Arm ratio and centromere index of $X$ chromosomes

The mean and standard error of arm ratio as well as centromere index (expressed as percentage) along with the result of the CD test of significance of X-chromosome based on 84 metaphase spreads of arsenic affected cattle and 24 normal cattle have been given in Table-2. It is evident from the Table-2 that the mean arm ratio of $\mathrm{X}$-chromosome was higher $(2.867 \pm 0.029)$ in normal cattle than that of arsenic affected cattle $(2.821 \pm 0.016)$ but it is reverse in case of centromere index value of X-chromosome $(27.248 \pm 0.029$ and $30.808 \pm 0.479)$. There was no significant difference of arm ratio and centromere index of X-chromosomes between arsenic affected cattle and normal cattle.

\section{Chromosomal abnormalities}

To find out any chromosomal abnormalities like chromatid breaks, centromeric association etc. in the autosomes and sex chromosomes of 25 metaphase chromosome spreads from each of 4 coded slides prepared from each of arsenic affected cattle were screened thoroughly. No such chromosomal abnormalities were found in arsenic affected cattle.
Table-2: The means with standard errors of the arm ratio and centromere index of X-chromosomes in normal and arsenic affected cattle.

\begin{tabular}{lcc}
\hline Groups & \multicolumn{2}{c}{ X-chromosome } \\
\cline { 2 - 3 } & Arm ratio & Centromere index \\
\hline Normal (24) & $2.867 \pm 0.029$ & $27.248 \pm 0.621$ \\
Arsenic affected & $2.821 \pm 0.016$ & $30.808 \pm 0.479$ \\
cattle (84) & & \\
\hline Numerics in parenthesis in Table-2 indicate the number of \\
observations
\end{tabular}

Literature in respect of chromosomal analysis of arsenic affected cattle is lacking. The present study will provide a reference for the same. However, in normal cattle, the result obtained by Tafro et al. [17], Balaji et al. [18], Ahmed et al. [19], Porsowal [20] collaborate with the present finding with respect to the number and morphology of chromosome and also to the arm ratio and centromere index [18]. Regarding chromosomal abnormalities, Leonard et al. [21] observed chromatid breaks in the metaphase chromosome of cattle intoxicated with heavy metals. Some acute and chronic toxicity of arsenic in humans and animals has been reported by Roy et al. [22]. Hematobochemical profiles of affected cattle at arsenic prone zone were also reported [23]. Increased frequency of sister chromatid exchange in human beings has been reported after exposure to arsenic [24] and borax [25]. Similarly, chromosomal aberrations were reported in cattle after exposure of bleomycin [26], bendiocarb, N-methylcarbamate pesticide [27], tolyfluanid, fungicide [28], and dioxins [29].

\section{Conclusion}

The chromosome analysis of arsenic affected cattle in West Bengal reported for the first time in this present study. The cytogenetic study on 21 arsenic affected cattle has allowed showing that arsenic had no significant effect on the chromosomal abnormalities in cattle. These results could serve as a baseline to compare the chromosome analysis with other toxic elements in cattle as well as in other species. The industrial pollution emitted into the environment may have a genotoxic character. Thus, cytogenetic examination of cattle may be a useful test for monitoring industrial pollution. Further studies are highly recommended to show the cytogenetic analysis after inducing arsenic on different age, sex, and breeds of cattle at a different concentration level.

\section{Authors' Contributions}

AKS planned and designed the study. SS, ND, PC, and PKP collected samples for study. SS carried out the work and wrote the manuscript. ND, RR, and RS helped during manuscript writing and cross checking. All authors read and approved the final manuscript. 


\section{Acknowledgments}

The authors are thankful to Dean WBUAFS, Kolkata for providing necessary facilities to conduct the present study. The fund for the study was provided by Department of Animal Genetics and Breeding, Faculty of Veterinary and Animal Sciences, West Bengal University of Animal and Fishery Science, Kolkata-37 (West Bengal).

\section{Competing Interests} interests.

The authors declare that they have no competing

\section{References}

1. Chowdhury, U.K., Biswas, B.K., Chowdhury, T.R., Samanta, G., Mandal, B.K., Basu, G.C., Chanda, C.R., Lodh, D., Saha, K.C., Mukherjee, S.K., Roy, S., Kabir, S., Quamruzzaman, Q. and Chakraborti, D. (2000) Ground water arsenic contamination in Bangladesh and West Bengal, India. Environ. Health Perspect., 108(5): 393-397.

2. Datta, B.K., Mishra, A., Singh, A., Sar, T.K., Sarkar, S., Bhatacharya, A., et al. (2010) Chronic arsenicosis in cattle with special reference to its metabolism in arsenic endemic village of Nadia district West Bengal India. Sci. Total. Environ., 409: 284-288.

3. Dash, J.R., Datta, B.K., Sarkar, S. and Mandal, T.K. (2013) Chronic arsenicosis in cattle: possible mitigation with $\mathrm{Zn}$ and Se. Ecotoxicol. Environ. Saf., 92: 119-122.

4. Barrett, J.C., Lamb, P.W., Wang, T.C. and Lee, T.C. (1989) Mechanisms of arsenic induced cell transformation. Biol. Trace Elem. Res., 21: 421-429.

5. Nakamuro, K. and Satayo, T. (1981) Comparative studies of chromosomal aberration induced by trivalent and pentavalent arsenic. Mutat. Res., 88: 73-80.

6. Norderson, I., Sweins, A. and Beckman, L. (1981) Chromosome aberrations in cultured human lymphocytes exposed to trivalent and pentavalent arsenic. Scand. J. Work Environ. Health, 7: 277-281.

7. Bencko, V., Wagner, V. and Wagnerova M. (1988) Immunological profiles in workers of a power plant burning coal rich in arsenic content. J. Hyg. Epidemiol. Microbial. Immunol., 32: 137-146.

8. Leonard, A. and Lauwerys, R.R. (1980) Carcinogenecity, teratogenecity and mutagenecity of arsenic. Mutat. Res., 75: 49-62.

9. Gradecka, D. (2001) Selected mechanisms of genotoxic effects of inorganic arsenic compounds. Int. J. Occup. Med. Environ. Health, 14(4): 317-328.

10. Khatun, M.R., Arifuzzaman, MD. and Ashraf, A. (2011) Karyotype for identification of genetic abnormalities in cattle. Asian. J. Anim. Vet. Adv., 6(2): 117-125.

11. Datta, B.K., Mishra, A., Singh, A., Sar, T.K., Sarkar, S., Bhatacharya, A., Chakraborty, A.K. and Mandal, T.K. (2010) Chronic arsenicosis in cattle with special reference to its metabolism in arsenic endemic village of Nadia district West Bengal. Indian. Sci. Total Environ., 409(2): 284-288.

12. Rana, T., Sarkar, S, Mondal, T.K., Bhattacharyya, K. and Roy, A. (2008) Arsenic residue in blood, urine and faeces sample from cattle in the Nadia district of West Bengal in India. Internet J. Vet. Med., 4(1).

13. Halnan, C.R.E. (1977) An improved technique for the preparation of chromosomes from cattle whole blood. Res. Vet. Sci., 22: 40-44.

14. Eldridge, F.E. (1985) Cytogenetics of livestock. AVI Publishing Co. Inc., Westport. Connecticut.

15. Gerasimchuk, A.V. (1975) A karyogram of cattle chromosomes. Tsitologia I Genet., 9(4): 299-302.

16. Snedecor, G.W. and Cochran, W.G. (1989) Statistical Methods. $8^{\text {th }}$ ed. Iowa State University Press, Ames.

17. Tafro, N., Sorazija, A., Bajramovic, N. and Adilovic, S. (1987) Cattle karyotype. Veterinaria, 36(3-4): 413-418.

18. Balaji, R., Gupta, B.R., Rao, G.R. and Narasa Reddy, G.V. (2006) Cytogenetic characterization of Deoni cattle. Indian J. Anim. Res., 40(1): 20-24.

19. Ahmed, I., Javed. K. and Sattar, A. (2004) Screening of breeding bulls of different breeds through karyotyping. Pak. Vet. J., 24(4): 190-192.

20. Porsowal, V.K. (1987) Chromosomes of cattle (Bos indicus linn.): Sahiwal and Gir breeds. M.Sc. Thesis, NDRI, Karnal.

21. Leonard, G.H, Deknudt, G. and Debackre, M. (1974) Cytogenetic investigations on leucocytes of cattle intoxicated with heavy metals. Toxicology, 2(3): 269-273.

22. Roy, D, Das, T.K and Vaswani, S. (2013) Arsenic: It's extent of pollution and toxicosis: An animal perspective. Vet. World, 6(1): 53-58.

23. Rana, T., Sarkar, S., Mandal, T. and Batabyal, S. (2008) Haematobiochemical profiles of affected cattle at arsenic prone zone in Haringhata block of Nadia District of West Bengal in India. Int. J. Haematol., 4: 1642-1657.

24. Rasmussen, R.E. and Menzel, D.B. (1997) Variation in arsenic induced sister chromatid exchange in human lymphocytes and lymphoblastoid cell lines. Mutat. Res., 386: 299-306.

25. Pongsavee, M. (2009) Genotoxic effects of borax on cultured lymphocytes. Southeast Asian J. Trop. Med. Public Health, 40(2): 411-418.

26. Luna, H.S., Ferrari, I., Luna, H., McManu, C., Padovani, C. R. and Rump, R. (2004) Different susceptibility to chromatid breaks induced by bleomycin in sub-fertile and fertile bovines. Reprod. Technol., 19(1): 97-101.

27. Holeckova, B., Sivikova, K. and Dianovsky, J. (2009) Effect of N-methylcarbamate pesticide bendiocarb on cattle lymphocytes after in vitro exposure. Acta. Biol. Hung., 60(2): 167-175.

28. Orosova, M., Holeckova, B., Sivikova, K. and Dianovsky, J. (2010) Effect of fungicide Euparen Multi (Tolyfluanid) on the induction of chromosomal aberrations in cultivated bovine lymphocytes. Acta. Biol. Hung., 61(4): 411-422.

29. Meo Di, G.P., Perucatti, A., Genualdo, V., CaputiJambrenghi, A., Rasero, R., Nebbia, C. and Iannuzzi, L. (2011) Chromosome fragility in dairy cows exposed to dioxins and dioxin-like PCBs. Mutagenesis, 26(2): 269-272. 